\title{
Reporting of medication errors by pediatric nurses
}

\author{
Derya Gök ${ }^{1}$, Hatice Yıldırım Sarı ${ }^{* 2}$ \\ ${ }^{1}$ Dr. Behçet Uz Children's Diseases and Surgery Training and Research Hospital, Konak-Izmir, Turkey \\ ${ }^{2}$ Nursing Department, Faculty of Health Sciences, Izmir Katip Celebi University, Cigli-Izmir, Turkey
}

Received: September 27, 2016

Accepted: November 23, 2016 Online Published: April 5, 2017

DOI: $10.5430 /$ jnep.v7n9p25

URL: https://doi.org/10.5430/jnep.v7n9p25

\begin{abstract}
Background and objective: Children have a higher risk of being exposed to medication errors and are more prone to harm due to reasons such as differences in their growth and development, and their physiological and psychological characteristics which are different from those of adults. The purpose of this study is to determine pediatric nurses' attitudes towards reporting of medication errors and causes of not reporting of medication errors and to determine their views on the incidence of medication errors.

Methods: The study was conducted in a Children's Hospital in the province of Izmir, with the participation of 179 pediatric nurses. To collect the data, two forms were used in the study, socio-demographic questionnaire and Questionnaire for Medication Errors.

Results: While 34.6\% $(n=62)$ of the nurses thought that medication errors never happened in the clinics over the past year. While $94.4 \%(n=169)$ of the participating nurses did not report any medication errors within the past year, $5.6 \%$ reported $1-2$ times. The highest proportion $(75.4 \%)(n=135)$ of the nurses, the reason for not reporting medication errors was the fear of receiving legal punishment.

Conclusions: Reporting medication errors is low level. In conclusion, the main reason for not reporting medication errors was the perception of receiving punishment. Implications for nursing and/or health policy: Education to nurses should be given at regular intervals and in small groups by using case samples. If the managers are to promote reporting, they should eliminate the perception of receiving punishment, and make necessary arrangements to develop non-accusatory culture aiming to learn from the results of reported errors.
\end{abstract}

Key Words: Medication error reporting, Medication errors, Medical errors, Pediatrics and medication errors, Nursing medication errors, Pediatric nursing

\section{INTRODUCTION}

Medication errors are of an important place in medical errors. It has been reported that 672,000 patients are injured and 98,000 patients die due to preventable medication errors each year. ${ }^{[1]}$ The World Health Organization (WHO) has emphasized that one in every ten patients is injured because of errors or adverse events during their hospital process in developed countries, that this rate is even higher in developing countries and that children are more at risk. ${ }^{[2]}$ Medication errors are a preventable cause of death, especially among the children. Children have a higher risk of being exposed to medication errors and are more prone to harm due to reasons such as differences in their growth and development, and their physiological and psychological characteristics which are different from those of adults. ${ }^{[3]}$ Preventable medication errors not only adversely affect human health but also increase the cost

\footnotetext{
* Correspondence: Hatice Yıldırım Sarı; Email: haticeyildirimsari@gmail.com; Address: Faculty of Health Sciences, Izmir Katip Celebi University, Cigli-Izmir, Turkey.
}

Published by Sciedu Press 
of healthcare. According to a report published in 2013, the cost of preventable medication errors in the United States (US) is at an average of \$ 20 million (between 15 and 28 million dollars). ${ }^{[4]}$ The European Medicines Agency has reported that the estimated annual cost of preventable medication errors in European countries varies between 4.5 and 21.8 billion euros. ${ }^{[5]}$

Medication errors occur as result of the combination of system- and human-induced causes. ${ }^{[1,6]}$ A lot many factors such as lack of the favorable environment, policies and procedures for the preparation of medicines, negative work culture, lack of effective communication between health workers, inadequate system through which medication is prescribed, fatigue, inadequate training and experience play a role in the occurrence of medication errors. ${ }^{[7-9]}$ In addition, that medication used has no pediatric forms and that calculation of drug doses for children in accordance with their weights is not accurately made may lead to medication errors too. ${ }^{[8]}$

Preventing patients admitted to hospitals for treatment from getting harm due to medication errors is the main task of those who provide health care services. The most important method to reduce errors is to report the error and to have it analyzed. ${ }^{[10]}$ In studies on the issue, it seems that reporting of medication errors is insufficient. ${ }^{[11]}$ It was found that nurses tend not to report medication errors due to various reasons. ${ }^{[9]}$ Y1lmaz $^{[12]}$ reported that nurses did not report medication errors for two reasons: (1) fear of the negative consequences of the error reporting $(29.9 \%)$, (2) fear of being accused of the error if medication errors inflict any harm to patients $(64.2 \%)$. In Manal and Hanan's ${ }^{[7]}$ study about nurses' perception of medication errors, it was determined that nurses did not report medication errors because they were scared that they might be scolded by nurse managers. Wang et al. ${ }^{[13]}$ reported that review of the hospital reporting system revealed that of those who said that they reported medication errors, some did not.

In all hospitals in Turkey, patient safety reporting systems aiming to report errors have been established. However, the data are not collected and evaluated in a single center. Therefore, data on the percentage of medication errors in pediatric patients, medication error-related injuries and deaths and the number of medication errors reported are obtained from a limited number of individual studies. In their study ${ }^{[14]}$ conducted on patient safety in a university hospital, Ünsal Altan et al. ${ }^{[14]}$ determined that $83.1 \%$ of the nurses did not report any errors within the last 12 months. In a similar study by Başbakkal, Taş, and Bal Yılmaz ${ }^{[15]}$ it was determined that the nurses reported only very few of the errors.

Harm caused by medication errors affects pediatric patients more adversely. In order to prevent pediatric patients' exposures to medication errors, reporting of medication errors which will make it possible to perform root cause analysis should be increased. Therefore, there is a need for studies to determine pediatric nurses' knowledge of and attitudes towards error reporting. In Turkey, there are a limited number of studies conducted on this issue. Among these studies are Törüner and Uysal's ${ }^{[16]}$ and Ozkan, Kocaman, and Öztürk's ${ }^{[17]}$ studies. In their study of 119 pediatric nurses, Törüner and Uysal ${ }^{[16]}$ concluded that many errors were not reported for various reasons although $88 \%$ of the nurses stated that they used the medication error reporting system. The nurses stated that due to following reasons they did not report medication errors: they were afraid that they might be accused if an adverse event occurred in patients $(52.9 \%)$, they might receive disciplinary punishment (42\%) and their colleagues might lose their confidence in them (50.4\%).

\subsection{Aim}

The purpose of this study is to determine pediatric nurses' attitudes towards reporting of medication errors and causes of not reporting of medication errors and to determine their views on the incidence of medication errors.

\subsection{Study questions}

(1) What is the pediatric nurses' knowledge level related to medication errors and reporting of medication errors?

(2) According to pediatric nurses, how frequently do medication errors occur?

(3) How frequently did pediatric nurses report medication errors?

(4) What are the reasons for pediatrics nurses' not reporting medication errors?

\section{Method}

\subsection{Study type}

The study is a descriptive study.

\subsection{Setting}

The study was conducted in a Children's Hospital in the province of Izmir. The hospital has 371 beds, 80 of which are in the intensive care units. The hospital serves approximately 582,216 outpatients and 18,133 inpatients a year. The hospital was deemed worthy of the TSE-ISO EN 9000 quality certificate in 2006. A safety reporting system has been used in the hospital since 2011. The safety reporting system includes medication safety, transfusion safety, surgery safety and others. Error reporting is made through the hospital information management system. The identity of the person 
reporting the error is not known, but the time and date of the reporting and the clinic where the reporting is made are known. The use of the safety reporting system is voluntary. Staff members can report errors by phoning or submitting a petition.

\subsection{Sampling}

In the hospital, 392 nurses were employed. Of them, 147 were employed in intensive care units, 130 in clinics and 115 in outpatient units. Of the nurses, those who worked in the outpatient clinics and operating theaters, who started working recently and who were in the orientation process were not included in the study. The sample size was determined as 184 at a $95 \%$ confidence level with a $\pm 5 \%$ margin of error. Survey forms for the study were responded by those 184 nurses on a voluntary basis. Five of the forms were not evaluated due to incomplete information, and thus the sample consisted of 179 nurses.

\subsection{Data collection tools}

To collect the data, two forms were used in the study.

Socio-demographic questionnaire: The questionnaire includes items questioning the nurses' age, gender, education status and employment status.

Medication errors reporting form: The form prepared in accordance with literature consists of 11 questions. The form was developed to determine pediatric nurses' views on medication errors, and the frequency and reporting of medication errors. The cases included in the form reflects each type of medication error (e.g., wrong dosage, wrong time). ${ }^{[7]}$

\subsection{Data collection}

Data collection forms to be used in the study were pilottested with five nurses. No changes were made on the forms after pilot testing. During the data collection phase, faceto-face interviews were held with the nurses working in the clinics and intensive care units. Of the nurses, those who agreed to participate in the study were informed about the importance of the study and then the forms indicating that they volunteered were obtained. In order to obtain objective results, questionnaires were left in the clinics and collected back on the same day.

\subsection{Data analysis}

The data were analyzed using the SPSS 20 software package. For the analysis, frequency, number and percentage, means and standard deviation were used.

\subsection{Study ethics}

To conduct the study, necessary permissions were obtained from Non-interventional Clinical Research Ethics Commit- tee of University (dated October 30, 2014 and numbered 228), and Izmir South Region Public Hospitals Association General Secretariat (dated January 6, 2015 and numbered 235923 79/044). The participants were assured that the data to be obtained with the data collection forms would not be used for any other purpose and would not be shared with third parties.

\subsection{Limitations of the study}

The study was conducted only in one children's hospital. The results are only valid for this hospital. A study with a larger sample including pediatric nurses in other hospitals can be carried out.

\section{Results}

Sociodemographic characteristics of the nurses participating in the study are as follows:

The mean age of the participating nurses was $35.25 \pm 6.1$. Of the nurses surveyed $(\mathrm{n}=101), 56.4 \%$ were in the $29-38$ age group, $24 \%(n=43)$ were in the $39-43$ age group, $19.6 \%$ $(\mathrm{n}=35)$ were in the 19-28 age group, $93.9 \%$ were female, $45.8 \%(n=82)$ had a graduate degree, $35.8 \%(n=64)$ had an associate degree, $12.3 \%(\mathrm{n}=22)$ had a high school degree, $6.1 \%(n=11)$ had a master degree, $49.2 \%(n=88)$ worked in the clinics, $44.1 \%(n=79)$ worked in the intensive care units, $6.7 \%(\mathrm{n}=12)$ worked in the emergency rooms, $71.5 \%(\mathrm{n}=$ $128)$ worked day and night shifts alternately, $21.2 \%(\mathrm{n}=38)$ always worked day shift, $7.3 \%(\mathrm{n}=13)$ always worked night shifts, $54.2 \%(\mathrm{n}=97)$ worked $41-50$ hours a week, $27.9 \%$ (n $=50)$ worked 40 hours a week, $17.9 \%(\mathrm{n}=32)$ worked 51 hours or more a week, $89.4 \%(\mathrm{n}=160)$ received education on patient safety, and $86 \%(\mathrm{n}=154)$ received education on medication safety.

In Table 1, approaches displayed by the nurses when they confronted medication errors were evaluated. Of the nurses, $62.6 \%(n=112)$ stated that they would report the administration of wrong medication error. In the case of failing to administer the medication to the patient, $97.2 \%(\mathrm{n}=174)$ of the nurses stated that they would not report the error. Of the near miss cases, the wrong medication order and wrong medication administration technique (route) were reported by $12.8 \%$ and $46.4 \%$ of the nurses respectively.

Table 2 shows that $98.3 \%(n=176)$ of the nurses surveyed agreed that errors resulting in patients' death should be reported. The rate of the participants who thought that medication errors which do not reach patients should be reported was $51.4 \%(n=92)$. The rate of the undecided participants in this case was $19 \%(\mathrm{n}=34)$. 
Table 1. Pediatric nurses' assessment of medication errors with case examples

\begin{tabular}{|c|c|c|c|c|c|c|c|}
\hline \multirow[b]{2}{*}{ Case Examples } & \multirow{2}{*}{$\begin{array}{l}\text { Type of the } \\
\text { medication } \\
\text { error }\end{array}$} & \multicolumn{2}{|c|}{$\begin{array}{l}\text { I report only to the } \\
\text { physician }\end{array}$} & \multicolumn{2}{|c|}{$\begin{array}{l}\text { I consider it as } \\
\text { medication error }\end{array}$} & \multicolumn{2}{|c|}{ I report it as an error } \\
\hline & & $\begin{array}{l}\text { Yes } \\
\text { Number } \\
\%\end{array}$ & $\begin{array}{l}\text { No } \\
\text { Number } \\
\%\end{array}$ & $\begin{array}{l}\text { Yes } \\
\text { Number } \\
\%\end{array}$ & $\begin{array}{l}\text { No } \\
\text { Number } \\
\%\end{array}$ & $\begin{array}{l}\text { Yes } \\
\text { Number } \\
\%\end{array}$ & $\begin{array}{l}\text { No } \\
\text { Number } \\
\%\end{array}$ \\
\hline $\begin{array}{l}\text { A patient is sent to medical center out the } \\
\text { hospital for MRI. Therefore, the patient's } \\
\text { intravenous ampicillin therapy scheduled at } \\
10 \text { o'clock is delayed } 2 \text { hours. }\end{array}$ & Wrong Time & $\begin{array}{l}165 \\
92.2\end{array}$ & $\begin{array}{l}14 \\
7.8\end{array}$ & $\begin{array}{l}18 \\
10.1\end{array}$ & $\begin{array}{l}161 \\
89.9\end{array}$ & $\begin{array}{l}5 \\
2.8\end{array}$ & $\begin{array}{l}174 \\
97.2\end{array}$ \\
\hline $\begin{array}{l}\text { You notice that the drug dose calculated in } \\
\text { the patient order form you have received } \\
\text { from the hospital information management } \\
\text { system is high. }\end{array}$ & Wrong Order & $\begin{array}{l}152 \\
84.9\end{array}$ & $\begin{array}{l}27 \\
15.1\end{array}$ & $\begin{array}{l}27 \\
15.1\end{array}$ & $\begin{array}{l}152 \\
84.9\end{array}$ & $\begin{array}{l}23 \\
12.8\end{array}$ & $\begin{array}{l}156 \\
87.2\end{array}$ \\
\hline $\begin{array}{l}\text { After inserting the intravenous catheter to } \\
\text { administer amphotericin B prescribed to } \\
\text { the patient for the first time, you visit other } \\
\text { patients to administer their drugs. When } \\
\text { you come back } 30 \text { minutes later, you see } \\
\text { that the patient has cyanosis on her hand } \\
\text { and around the lips. }\end{array}$ & $\begin{array}{l}\text { Failure to } \\
\text { monitor the } \\
\text { effects of drugs }\end{array}$ & $\begin{array}{l}107 \\
59.8\end{array}$ & $\begin{array}{l}72 \\
40.2\end{array}$ & $\begin{array}{l}76 \\
42.5\end{array}$ & $\begin{array}{l}103 \\
57.5\end{array}$ & $\begin{array}{l}70 \\
39.1\end{array}$ & $\begin{array}{l}109 \\
60.9\end{array}$ \\
\hline $\begin{array}{l}\text { During the nurse visit at } 8 \text { o'clock in the } \\
\text { morning, you find out that night dose of } \\
\text { ventolin was not administered to the } \\
\text { asthma patient because the patient was } \\
\text { sleeping. }\end{array}$ & $\begin{array}{l}\text { Failure to } \\
\text { administer the } \\
\text { drug to the } \\
\text { patient }\end{array}$ & $\begin{array}{l}101 \\
56.4\end{array}$ & $\begin{array}{l}78 \\
43.6\end{array}$ & $\begin{array}{l}94 \\
52.5\end{array}$ & $\begin{array}{l}85 \\
47.5\end{array}$ & $\begin{array}{l}32 \\
17.9\end{array}$ & $\begin{array}{l}147 \\
82.1\end{array}$ \\
\hline $\begin{array}{l}\text { Although the patient order requires } \\
\text { administering } 2 \text { cc of diluted ceftriaxone, } \\
\text { you administer } 4 \text { cc of ceftriaxone. You } \\
\text { notice your error during the next treatment. }\end{array}$ & $\begin{array}{l}\text { Wrong } \\
\text { dosage/Wrong } \\
\text { preparation }\end{array}$ & $\begin{array}{l}78 \\
43.6\end{array}$ & $\begin{array}{l}101 \\
56.4\end{array}$ & $\begin{array}{l}115 \\
64.2\end{array}$ & $\begin{array}{l}64 \\
35.8\end{array}$ & $\begin{array}{l}37 \\
20.7\end{array}$ & $\begin{array}{l}142 \\
79.3\end{array}$ \\
\hline $\begin{array}{l}\text { During the shift change at } 4 \text { P.M., you } \\
\text { notice that drug administration rate was set } \\
\text { at } 215 \mathrm{ml} / \mathrm{h} \text { instead of } 125 \mathrm{ml} / \text { hour at } 2 \\
\text { P.M. in the infusion pump of the catheter } \\
\text { inserted into the vein of the patient having } \\
\text { total parenteral nutrition therapy. }\end{array}$ & $\begin{array}{l}\text { Wrong drug } \\
\text { administration } \\
\text { rate }\end{array}$ & $\begin{array}{l}77 \\
43.0\end{array}$ & $\begin{array}{l}102 \\
57.0\end{array}$ & $\begin{array}{l}117 \\
65.4\end{array}$ & $\begin{array}{l}62 \\
34.6\end{array}$ & $\begin{array}{l}51 \\
28.5\end{array}$ & $\begin{array}{l}128 \\
71.5\end{array}$ \\
\hline $\begin{array}{l}\text { You notice redness and itching on the } \\
\text { patient's arm you administered Isolayte P } \\
\text { solution an hour ago, and you notice that } \\
\text { the expiration date of the solution is past. }\end{array}$ & $\begin{array}{l}\text { Administration } \\
\text { of expired } \\
\text { drugs }\end{array}$ & $\begin{array}{l}55 \\
30.7\end{array}$ & $\begin{array}{l}124 \\
69.3\end{array}$ & $\begin{array}{l}121 \\
67.6\end{array}$ & $\begin{array}{l}58 \\
32.4\end{array}$ & $\begin{array}{l}89 \\
49.7\end{array}$ & $\begin{array}{l}90 \\
50.3\end{array}$ \\
\hline $\begin{array}{l}\text { You and the nurse who has recently started } \\
\text { working in the hospital and accompanies } \\
\text { you on the day shift notice that the patient } \\
\text { you provide care has undergone respiratory } \\
\text { arrest. Your investigation reveals that your } \\
\text { partner administered "an ampoule of } \\
\text { aldolan" instead of "an ampoule of } \\
\text { andolor". }\end{array}$ & $\begin{array}{l}\text { Wrong } \\
\text { medication }\end{array}$ & $\begin{array}{l}54 \\
30.2\end{array}$ & $\begin{array}{l}125 \\
69.8\end{array}$ & $\begin{array}{l}107 \\
59.8\end{array}$ & $\begin{array}{l}72 \\
40.2\end{array}$ & $\begin{array}{l}112 \\
62.6\end{array}$ & $\begin{array}{l}67 \\
37.4\end{array}$ \\
\hline $\begin{array}{l}\text { You notice that the student nurse under } \\
\text { your supervision has added Ventolin in the } \\
\text { injector to the IV pump set via the second } \\
\text { route, which in fact should be administered } \\
\text { in the nebulizer. }\end{array}$ & Wrong route & $\begin{array}{l}48 \\
26.8\end{array}$ & $\begin{array}{l}131 \\
73.2\end{array}$ & $\begin{array}{l}117 \\
65.4\end{array}$ & $\begin{array}{l}62 \\
34.6\end{array}$ & $\begin{array}{l}83 \\
46.4\end{array}$ & $\begin{array}{l}96 \\
53.6\end{array}$ \\
\hline
\end{tabular}

While $34.6 \%(n=62)$ of the nurses thought that medication errors never happened in the clinics over the past year, $40.8 \%$ $(\mathrm{n}=73)$ thought a few times, $11.7 \%(\mathrm{n}=21)$ thought once a month or less often, $6.1 \%(n=11)$ thought a few times a month, $5.6 \%(\mathrm{n}=10)$ thought a few times a week, and $1.1 \%(n=2)$ thought every day. While $94.4 \%(n=169)$ of the participating nurses did not report any medication errors within the past year, $5.6 \%$ reported $1-2$ times. While $50.3 \%$ 
( $\mathrm{n}=90)$ of the participating nurses believed that medication opposite.

error reporting is satisfactory, $49.7 \%(n=89)$ thought the

Table 2. Medication errors to be reported or not to be reported according to the pediatric nurses

\begin{tabular}{|c|c|c|c|c|c|c|}
\hline \multirow{2}{*}{ Medication Errors } & \multicolumn{2}{|c|}{ To be reported } & \multicolumn{2}{|c|}{ Not to be reported } & \multicolumn{2}{|c|}{ Undecided } \\
\hline & Number & $\%$ & Number & $\%$ & Number & $\%$ \\
\hline $\begin{array}{l}\text { A medication error has occurred, but there is no harm to the patient } \\
\text { because it has not reached the patient. }\end{array}$ & 92 & 51.4 & 53 & 29.6 & 34 & 19.0 \\
\hline The medication error has reached the patient but has caused no harm. & 152 & 84.9 & 11 & 6.1 & 16 & 8.9 \\
\hline The medication error has reached the patient and it requires monitoring. & 160 & 89.4 & 7 & 3.9 & 12 & 6.7 \\
\hline $\begin{array}{l}\text { The medication error causes a temporary harm to the patient and requires } \\
\text { treatment or intervention. }\end{array}$ & 173 & 96.6 & 3 & 1.7 & 3 & 1.7 \\
\hline $\begin{array}{l}\text { The medication error requires the patient's hospitalization and causes a } \\
\text { temporary harm to the patient. }\end{array}$ & 172 & 96.1 & 4 & 2.2 & 3 & 1.7 \\
\hline The medication error causes a permanent harm to the patient. & 174 & 97.2 & 1 & 0.6 & 4 & 2.2 \\
\hline $\begin{array}{l}\text { There is a possibility that the medication error might result in death and } \\
\text { an intervention is required to keep the patient alive. }\end{array}$ & 173 & 96.6 & 2 & 1.1 & 4 & 2.2 \\
\hline The medication error results in death. & 176 & 98.3 & 1 & 0.6 & 2 & 1.1 \\
\hline
\end{tabular}

As is seen in Table 3, for the highest proportion $(75.4 \%)$ (n $=135$ ) of the nurses, the reason for not reporting medication errors was the fear of receiving legal punishment. While for $74.9 \%(n=134)$ of them, the reason was the fear of being perceived negatively by the management, the reason was the fear of being assigned somewhere else for $67.0 \%(n=120)$ of them. The insecure reporting system was considered as a reason by $45.8 \%(n=82)$ of the participants.

Table 3. Reasons of not reporting medication errors according to pediatric nurses

\begin{tabular}{|c|c|c|c|c|c|c|}
\hline \multirow{2}{*}{ Reasons } & \multicolumn{2}{|l|}{ Yes } & \multicolumn{2}{|l|}{ No } & \multicolumn{2}{|c|}{ Undecided } \\
\hline & Number & $\%$ & Number & $\%$ & Number & $\%$ \\
\hline Fear of receiving legal punishment & 135 & 75.4 & 33 & 18.4 & 11 & 6.1 \\
\hline Fear of being perceived negatively by the management & 134 & 74.9 & 32 & 17.9 & 13 & 7.3 \\
\hline Fear of receiving disciplinary punishment & 129 & 72.1 & 35 & 19.6 & 15 & 8.4 \\
\hline Fear of being assigned somewhere else & 120 & 67.0 & 44 & 24.6 & 15 & 8.4 \\
\hline $\begin{array}{l}\text { If the patient has developed a serious adverse effect, fear } \\
\text { of being legally investigated }\end{array}$ & 116 & 64.8 & 41 & 22.9 & 22 & 12.3 \\
\hline Fear of losing teammates' trust in them & 113 & 63.1 & 49 & 27.4 & 17 & 9.5 \\
\hline Fear of losing patients' trust in them & 110 & 61.5 & 55 & 30.7 & 14 & 7.8 \\
\hline Difficulties in the reporting process & 107 & 59.8 & 40 & 22.3 & 32 & 17.9 \\
\hline No chance to make revisions in reports & 96 & 53.6 & 43 & 24.0 & 40 & 22.3 \\
\hline Fear of not being supported by the management & 90 & 50.3 & 54 & 30.2 & 35 & 19.6 \\
\hline Insecure reporting system & 82 & 45.8 & 60 & 33.5 & 37 & 20.7 \\
\hline
\end{tabular}

\section{Discussion}

The discussion of the present study conducted to determine whether the pediatric nurses report medication errors, reasons for reporting or not reporting medication errors and the frequency of medication errors was based on the following research questions:

Study Question 1. What is the pediatric nurses' knowledge level related to medication errors and reporting of medication

Published by Sciedu Press errors?

The majority of the pediatric nurses participating in the study answered the cases with medication errors correctly. Based on these results, it can be said that the nurses working in the pediatric clinics usually know what medication errors are. Nearly half of the nurses $(47.5 \%)$ did not consider the event in which drug was not administered to the patient as a medication error. In Lan et al.'s study ${ }^{[18]}$ conducted to 
determine the pediatric nurses' knowledge level regarding medication errors, $72.9 \%$ of the nurses answered the questions correctly. In Yilmaz's thesis study ${ }^{[12]}$ on reporting medication errors, $80.5 \%$ of the nurses stated that they were aware of medication errors. The nurses, in general, knew what medication errors are. However, when the question was asked in relation to case samples, "the administration of drug at a wrong time", "wrong order" and "failure to monitor the effects of drugs" were not considered as medication errors by the nurses (89.9\%, $84.9 \%$ and $57.5 \%$ respectively). These results show us that nurses did not notice the medication errors during clinical practices well enough. Therefore, if nurses are taught about medication errors during medication safety or patient safety trainings, using case samples can help them notice medication errors more easily.

In Table 1 reported by the second lowest proportion of the nurses $(12.8 \%)$ was a near miss error. In Shaw et al.'s study ${ }^{[19]}$ investigating reporting of 597 medication errors in pediatric emergency rooms, the rate of near miss errors was the lowest (30\%). In Sears, Pallas, Stevens, and Murphy's study, ${ }^{[20]}$ of the 372 reported errors, 127 were potential errors in other words near miss errors. In a study including pediatricians, the least reported errors were near miss errors $(7 \%) .{ }^{[21]}$ There may be various reasons of insufficient reporting of near miss errors. The nurses may not have perceived the errors which neither reached the patient nor caused the patient any harm as an error, or even if they considered it as an error, they may have disregarded it because it did not reach the patient. Another reason for not reporting near miss errors is that the nurses may have thought that reporting would take much time. Fear of being accused of making the error may be another reason for not reporting the error. ${ }^{[22]}$ Reporting of near miss errors which have not reached the patient is important. Reporting of near miss errors contributes to the root cause analysis of medication errors, as a result of which the underlying cause of the error can be revealed, and regulations to prevent similar errors from happening again can be developed. ${ }^{[23]}$

Study Question 2. According to pediatric nurses, how frequently do medication errors occur?

Study Question 3. How frequently did pediatric nurses report medication errors?

In the present study, $40.8 \%$ of the nurses reported that medication errors occurred in the clinics a few times a year. However, only 10 people reported 1-2 errors within the past year, which suggests that the number of the medication errors reported is fewer than the actual ones. In Wang et al.'s study, ${ }^{[13]}$ $75 \%$ of the nurses stated that they reported the medication errors; however, more than half of those errors were not recorded in the hospital reporting system.

In the hospital where this present study was conducted, the number and routes of daily drug administration are as follows: 800-1000 intravenously, 800 through the oral route, 300-350 through inhalation and 15-20 through the intramuscular route. However, although identified error rates in the research were much higher, only 10 of the nurses participating in this study stated that they reported 1-2 errors. In their study, Özkan et al. ${ }^{[17]}$ observed 1686 drug administrations in children and determined 475 errors. Sears et al. ${ }^{[20]}$ conducted a study including 440 inpatient children to investigate medication errors which occurred in a three-month period and reported that 372 errors were reported. In their study conducted in a hospital in China, Ding et al. ${ }^{[24]}$ observed that intravenous medication errors occurred at least once a day. In their 24-hour observation study including 117 intensive care units in 27 countries, Valentin et al. ${ }^{[25]}$ identified 861 parenteral medication errors. In Otero, Leyton, Mariani and Cernadas' $\mathrm{s}^{[26]}$ study of 1588 medication administration cases, the medication error rate was $11.4 \%$. These results suggest that medication errors occur very often, but only some of them are noticed and a smaller number of them are reported.

In the present study, $94.4 \%$ of the nurses stated that they did not report any errors. This rate is higher than the rates in similar studies in the literature. In general, nurses knew what medication errors were and which events should be reported. However, they did not actively use the error reporting system. In Wang et al.'s study, ${ }^{[13]} 50.9 \%$ of the nurses stated that they did not report any medication errors over the last year. In Törüner and Uysal's study, ${ }^{[16]} 47.9 \%$ of the participants stated that they reported errors using the system. In Chiang, Lin, Hsu and Ma's study, ${ }^{[27]} 52.4 \%$ of the nurses stated that they did not report any medication errors. Although the establishment of the error reporting system in hospitals in Turkey was realized in 2011, regulations on the types and reporting of medication errors were put into effect after the Quality Standards in Health Version 5 was published in 2015. ${ }^{[28]}$ Therefore, it is believed that error-reporting culture has not been adequately developed among the health professionals in the hospital. What is more, as is shown in Table 3, the nurses' fear of being punished legally drastically reduced the reporting of medication errors.

Of the nurses participating in the study, 50.3\% thought that reporting of medication errors was adequate. In You, Choe, Park, Kim and Son's study, ${ }^{[29]} 47.8 \%$ of the nurses stated that the number of medication errors reported was $20 \%$ less than the number of actual errors, which suggests that nurses refrained from reporting the errors for one reason or another. In Lan et al.'s study, ${ }^{[18]}$ the rate of the pediatric nurses reporting 
medication errors was determined as $79.4 \%$. This relatively high rate is probably because hospital managements have tended not to punish those who report medication errors in recent years.

Study Question 4. What are the reasons for pediatrics nurses' not reporting medication errors?

Among the reasons for nurses' not reporting medication errors, the one which takes the first place is the fear of receiving legal punishment $(75.4 \%)$. While $74.9 \%$ of the nurses did not report the errors due to fear of being perceived negatively by the management, $67 \%$ did not report them due to fear of being assigned somewhere else (see Table 3). Fear of losing the trust of their teammates and fear of losing the trust of their patients were among the other reasons why the nurses did not report medication errors. Another reason for not reporting medication errors by almost half of the nurses was that it was not possible to make revisions in the reports or in the medication-error reporting system. In Törüner and Uysal's study, ${ }^{[16]} 52.9 \%$ of the nurses did not report errors due to the fear of being accused of the error if medication errors inflicted any harm to patients, $50.4 \%$ due to the fear of losing their teammates' trust and $42 \%$ due to the fear of receiving punishment. In Manal and Hannan's study ${ }^{[7]}$ conducted with clinical and intensive care nurses, $76.5 \%$ and $67.6 \%$ of the nurses respectively did not report medication errors because they were scared of nurse managers, and $54.8 \%$ and $46.5 \%$ of them respectively did not report medication errors for fear of receiving disciplinary punishment or losing their job. Cousins, Gerrett and Warner ${ }^{[30]}$ conducted a study on the reporting of medication-related events and determined that reporting increased by about $50 \%$ each year between 2005 and 2010. This is probably because not only has employees' awareness of patient safety and error reporting increased but also culture-making efforts on this issue have been made. By nature, human beings are prone to make mistakes. The aim is to minimize errors and to determine them before they cause the patient any harm. Nurses refrain from error reporting for fear of being misunderstood by the managers or receiving punishment. İnceoğlu ${ }^{[31]}$ stated that individuals' exhibiting positive or negative attitudes towards events might be associated with the expectation of getting reward or punishment.

\section{Conclusion}

Wrong drug preparation, wrong drug administration route and wrong dosage were considered as medication errors by $90.5 \%(\mathrm{n}=162), 89.9 \%(\mathrm{n}=161)$ and $89.9 \%(\mathrm{n}=161)$ of the participating nurses respectively. Failure to follow the effects of drugs, failure to administer the drug to the patient, administration of drugs at a wrong time and wrong ordering

Published by Sciedu Press of drugs were not considered medication errors by $27.4 \%$ $(n=49), 23.5 \%(n=42), 18.4 \%(n=33)$ and $18.4 \%(n=$ 33 ) of the participating nurses respectively. Evaluation of the case examples-related results revealed that the rates of the nurses who did not consider administration of drugs at a wrong time $(89.9 \%)$, wrong ordering of drugs $(84.9 \%)$ and failure to monitor the effects of drugs $(57.5 \%)$ as errors were high. The majority of the nurses participating in the present study believe that if a medication error reached the patient, then it should be reported $(84.9 \%-96.6 \%)$. The rate of the nurses who thought that serious errors resulting in deaths should be reported was $98.3 \%$. It was concluded that the rate of the nurses who reported medication errors last year was rather low (5.6\%). The percentage of those who thought that near miss errors should be reported was low. Among the reasons for not reporting medication errors were the fear of receiving legal punishment $(75.4 \%)$, the fear of being perceived negatively by the management $(74.9 \%)$, fear of receiving disciplinary punishment $(72 \%)$ and fear of being assigned somewhere else $(67.0 \%)$. Fear of losing the trust of the teammates was also among the major reasons of not reporting errors. In conclusion, the main reason for not reporting medication errors was the perception of receiving punishment.

\section{IMPLICATIONS FOR NURSING AND/OR HEALTH POLICY}

According to the participating nurses' statements, the majority of them received education on medication safety and patient safety; however, there were some shortcomings in noticing and reporting medication errors. Therefore, education on this issue should be given at regular intervals and in small groups by using case samples. The study results demonstrated that reporting of near miss errors should be encouraged. Studies show that pediatric patients are more vulnerable to medication errors and are affected by the negative consequences of these errors more. In the present study, heavy workload was seen as the main cause of the errors. Taking all these into account, the ministry of health can develop policies to reduce the number of patients per nurse in children's hospitals. Attempts to reduce the number of patients per nurse should be made not only in pediatric clinics but also in intensive care units. If physicians' medication orders (especially high-risk drugs, chemotherapeutic drugs, etc.) are checked by the pharmacist after they are entered into the computer system, this can help prevent errors from reaching the patient. To achieve this purpose, an effective communication between physicians, nurses and pharmacists should be ensured, and approaches to strengthen teamwork should be adopted. Among the most important reasons for 
not reporting errors are the fear of receiving punishment and being misunderstood by the management. If the managers are to promote reporting, they should eliminate the perception of receiving punishment, and make necessary arrangements to develop non-accusatory culture aiming to learn from the results of reported errors.

\section{ACKNOWLEDGEMENTS}

The authors thank the nurses at the hospital.

\section{CONFLICTS OF INTEREST Disclosure}

The authos declared no potential conflicts of interest with respect to the research, authorship, and/or publication of this article.

\section{REFERENCES}

[1] Mattei JL, Gillespie GL. Pediatric emergency nurses' self-reported medication safety practices. Journal of Pediatric Nursing. 2013; 28: 596-602. PMid:23583361 https://doi.org/10.1016/j.pe dn.2013.03.005

[2] World Health Organization, Reporting And Learning Systems For Medication Errors: The Role Of Pharmacovigilance Centres. 2014.

[3] Stavroudis TA, Shore AD, Morlock L, et al. NICU medication errors: identifying a risk profile for medication errors in the neonatal intensive care unit. Journal of Perinatology. 2010; 30: 459-468. PMid:20043010 https://doi.org/10.1038/jp. 2009.186

[4] Aitken M. Avoidable costs in U.S. healthcare the $\$ 200$ billion opportunity from using medicines more responsibly. IMS Institute for Healthcare Informatics. 2013; 20-21 p.

[5] European Medicines Agency. Session 2 Reporting Operational definition of medication error for EU reporting requirements Medication-errors workshop. Available from: http://www.ema.europa.eu/docs/en_GB/document_librar y/Presentation/2013/03/WC500139871.pdf (19.08.2015)

[6] Orgeas MG, Philippart F, Bruel C, et al. Owerview of medical errors and advers events. Annals of Intensive Care a Springer Open Journal. 2012; 2(2): 1-9.

[7] Manal B, Hanan A. Medication errors, causes, and reporting behaviors as perceived by nurses. Journal of Pharmaceutical and Biomedical Sciences. 2012; 19(17): 1-7.

[8] Bertsche T, Bertsche A, Krieg EM, et al. Prospective pilot intervention study to prevent medication errors in drugs administered to children by mouth or gastrictube: a programme of nurses, physicians and parents. Quality \& Safety in Health Care. 2010; 19(26): 1-5.

[9] Küçükakça G. Investigating Knowledge Levels of Nurses, Working in Surgical Clinics, About High Risk Medicines and Their Attitudes and Behaviors Regarding Medication Errors, Unpublished Master Thesis, Atatürk University Health Science Instute, Erzurum. 2013 81.

[10] Seren İntepeler Ş, Dursun M. Medication Error and Medication Error Reporting Systems. Journal of Anatolia Nursing and Health Sciences. 2012; 15(2): 129-135.

[11] Uçar N, Yıldırım G, Eser D, et al. Determination of medical error reportings at day and night shifts. Journal of The Turkish Society of Intensive Care. 2013; 11: 93-100.

[12] Yilmaz A. Perceptions of nurses regarding barrier on medication administration error reporting. Unpublished $\mathrm{PhD}$ Thesis. Hacettepe University Social Science Instute, Ankara. 2009; 265.

[13] Wang X, Liu K, You L, et al. The relationship between patient safety culture and adverse events: a quastionnaire survey. International Journal of Nursing Studies. 2014; 51: 1114-1122. PMid:24418106 https://doi.org/10.1016/j.ijnurstu.2013.12.007
[14] Ünsal Altan Ş, Dönmez S, Taşçı Duran E. Investigation of Patient Safety Culture of Nurses Working in The University Hospital. Florance Nightingale Journal of Nursing. 2013; 21(3): 172-180.

[15] Başbakkal Z, Taş F, Bal Yılmaz H. A Study on the Pediatric Nurses' Opinions About Patient Safety Culture. Ege Pediatri Bülteni. 2009; 16(2): 87-93.

[16] Töruner EK, Uysal G. Causes, reporting, and prevention of medication errors from a pediatric nurse perspective. Australian Journal Of Advanced Nursing. 2012; 29(4): 29-35.

[17] Özkan S, Kocaman G, Öztürk C. Effect of strategies for preventing medication administration errors in pediatric inpatients. Turkish Archives of Pediatrics. 2013; 48: 299-302.

[18] Lan Y, Wang KW, Yu S, et al. Medication errors in pediatric nursing: assesment of nurses' knowledge and analysis of the consequences of errors. Nurse Education Today. 2014; 34: 821-828. PMid:23938094 https://doi.org/10.1016/j.nedt.2013.07.019

[19] Shaw KN, Lillis KA, Ruddy RM, et al. Reported medication events in paediatric emergency research network: sharing to improve patient safety. Emergency Medicine Journal. 2012; 30(10): 815-819. PMid:23117714 https://doi.org/10.1136/emermed-2012-2 01642

[20] Sears K, Pallas LO, Stevens B, et al. The relationship between the nursing work enviroment and occurrence of reported paediatric medication administration errors: a pan Canadian study. Journal of Pediatric Nursing. 2013; 28: 351-356. PMid:23290866 https : //doi.org/10.1016/j.pedn.2012.12.003

[21] Garbautt J, Brownstein DR, Klein EJ, et al. Reporting and disclosing medical errors pediatricians' attitudes and behaviors. Archives of Pediatric and Adolescent Medicine. 2007; 161(2): 179-185. PMid:17283304 https://doi.org/10.1001/archpedi.161.2 .179

[22] MacPhee E, Sherrard H. An innovative approach to"near miss' capture for improvement to patient safety. A Canadian Patient Safety Institue Studentship Project. University of Ottawa Heart Institue. 2007; 1-41 p.

[23] Cheung K. Learning From Medication Errors Through A Nationwide Reporting Programme, Doktora Tezi, Scientific Institute for Quality in Healthcare and Department of Clinical Pharmacy, Radboud University Medical Center, Nijmegen. 215.

[24] Ding Q, Barker KN, Flynn EA, et al. Incidence of intravenous medication errors in Chinese Hospital. Value in Health Regional Issues. 2015; 6: 33-39. https://doi.org/10.1016/j.vhri.2015.03 .004

[25] Valentin A, Capuzzo M, Guidet B, et al. Errors in administration of parenteral drugs in intensive care units: multinational prospective study. BMJ. 2009; 338 (b814). PMid:19282436 https ://doi.or $\mathrm{g} / 10.1136 / \mathrm{bmj} \cdot \mathrm{b} 814$

[26] Otero P, Leyton A, Mariani G, et al. Medication errors in pediatric inpatients: prevelance and results of a prevention program. 
American Academy of Pediatrics. 2008; 122: 737-743. https: //doi.org/10.1542/peds.2008-0014

[27] Chiang H, Lin S, Hsu S, et al. Factors determining hospital nurses' failures in reporting medication errors in taiwan. Nursing Outlook. 2010; 58: 17-25. PMid:20113751 https://doi.org/10.1016/j. outlook.2009.06.001

[28] Sağlikta hizmet kalite standartları-hastane seti versiyon 4. Available from: http://www.kalite.saglik.gov.tr/content/files /duyurular_2011/2011/16_mart_2011/ek122082013.pdf (28.05.2015)
[29] You M, Choe M, Park G, et al. Perceptions regarding medication administration errors among hospital staff nurses of South Korea. International Journal for Quality in Health Care. 2015; 27(4): 276-283. PMid:26054575 https://doi.org/10.1093/intqhc/mzv036

[30] Cousins DH, Gerrett D, Warner B. A review of medication incidents reported to the National Reporting and Learning System in England and Wales over 6 years. British Journal of Clinical Pharmacology. 2012; 74(4): 597-604. PMid:22188210 https://doi.org/10.1 $111 / j .1365-2125.2011 .04166 . x$

[31] İnceoğlu M. Tutum Algı İletişim, Beykent Üniversitesi Yayınevi, İstanbul. 2010. 